\title{
Adjuvant treatment of ovarian carcinoma with tranexamic acid
}

\author{
BIRGER ÅSTEDT \\ From the Department of Obstetrics and Gynaecology, University of Lund, Allmänna Sjukhuset, Malmö and \\ Lasarettet, Lund, Sweden
}

The growth of a tumour, like that of any normal tissue structure, depends on its vascular supply. Malignant tumours possess coagulative properties that cause deposition of fibrin around them. Such fibrin is a necessary matrix for proliferating tumour vessels. As in wound repair, old residual fibrin must afterwards be removed. This is done by the fibrinolytic system which, in tumours, is initiated by a tumour-plasminogen activator. This enzyme has recently attracted increasing attention.

\section{Tumour-plasminogen activator}

The existence of a tumour-plasminogen activator has long been known. At the beginning of this century pioneers in tissue culture showed that pieces of tumour could dissolve coagulated substrate. But nothing was known about the position or importance of the activators in the fibrinolytic system. The plasminogen activators were for a long time obstacles to research in tissue culture because they lysed the coagulated substrate and thereby drowned the cultivated pieces of tissue. ${ }^{12}$ This was finally overcome by adding inhibitors of fibrinolysis to the culture medium, which prevented dissolution of the medium. ${ }^{34}$

In recent years it has been shown that malignant transformation by oncogenic viruses or carcinogenic substances of certain normal mammalian cells in culture is followed by abundant release of plasminogen activators, in contrast to their untransformed counterparts. ${ }^{56}$ We have found that in organ cultures of normal human ovaries there is very little release of plasminogen activators, while malignant tumours originating in the same organ produce large amounts of tumour-plasminogen activator.? By culturing large amounts of activator-producing ovarian tumours and with the use of different chromatographic methods, particularly affinity chromatography on para-aminobenzamidine, we succeeded in obtaining pure tumour-plasminogen activator from the culture medium. ${ }^{8}$
We also succeeded in raising a monospecific antiserum to urokinase. ${ }^{9}$ An interesting finding was that urokinase and tumour-plasminogen activator were immunologically identical. They were also similar in other respects, such as the molecular forms in which they occur. ${ }^{8}$ This meant that much of the cumulative knowledge about urokinase applies also to the tumour-plasminogen activator. Thus it could be shown that the activation of plasminogen initiated by the tumour-plasminogen activator could be effectively inhibited by the fibrinolytic inhibitor tranexamic acid.

\section{Effect of tranexamic acid on neoplasms}

The effect of tranexamic acid on neoplasms was first studied in nude mice, which have no thymus and to which human tumours can be transplanted. The experiments were facilitated by the fact that the animals like to drink tranexamic acid. We found that when they drank the tranexamic acid the growth of the tumour was retarded compared with controls. In experimental tumours producing ascitic fluid the rate of production decreased. Our results agreed with those reported by others. In additional experiments we found no evidence that tranexamic acid had any influence on DNA synthesis.

Our aim in the treatment of patients with malignant tumours, therefore, was to interfere with the coagulative as well as the fibrinolytic properties of the tumour to bring about an anti-neoplastic effect. ${ }^{1011}$ We gave heparin to prevent deposition of fibrin but it never stopped deposition entirely. We then gave tranexamic acid (Cyklokapron) to inhibit fibrinolysis and to prevent dissolution of residual old fibrin. In all patients given this combined treatment with heparin and tranexamic acid the tumour was always advanced and all conventional treatments had failed. In some patients prolonged treatment had a static effect with encapsulation of the tumour in a fibrinoid-like substance. This encapsulation raised the question whether it might 
be better to treat the patient with tranexamic acid alone. ${ }^{10}$

In an early clinical study we selected 42 patients with various tumours in advanced stages with widespread metastases. All had been operated on and treated with radiation and cytostatics, despite which the lesions had progressed. The Karnofsky performance index was less than 40 -that is, the patients could not leave hospital. They were given tranexamic acid $4 \mathrm{~g}$ daily. Out of the 42 patients 27 were able to leave the hospital for various periods. The Karnofsky performance index was estimated to be $60-100$. This early study was thus simply of the amount of clinical improvement as measured by the Karnofsky scale. We also found that in patients with ascites the production of fluid regressed.

The regression of ascites or pleural effusions was studied in 16 other patients with various advanced tumours. Some of them were on chemotherapy, which had failed to inhibit their ascites or effusion. When supplementary tranexamic acid was given the ascites or effusion completely regressed in six patients. The interval between laparocenteses or thoracocenteses was prolonged in eight patients and two did not respond.

We studied in a new series of 17 patients with advanced ovarian carcinoma the effect of tranexamic acid combined with Alkeran. We have used Alkeran (mephalan) for many years in a single-drug regimen as an infusion of $1 \mathrm{mg} / \mathrm{kg}$ body-weight every fourth week for one year and then every sixth week for a further year. We gave tranexamic acid $6 \mathrm{~g}$ daily. Follow-up was for $2 \frac{1}{2}$ years. Before this course of treatment was given all patients had been operated on and the histology of their tumour classified (see Table).

Table Type of primary ovarian carcinoma in 17 patients according to classification of International Federation of Gynecology and Obstetrics (FIGO)

\begin{tabular}{ll}
\hline Tumour & $\begin{array}{l}\text { No. of } \\
\text { patients }\end{array}$ \\
\hline Epithelial & \\
(IC) Serous cystadenocarcinoma & 1 \\
$\quad$ Stage II & 6 \\
Stage III & 5 \\
$\quad$ Stage IV & 2 \\
(IIC) Mucinous cystadenocarcinoma & \\
$\quad$ Stage III & 1 \\
(V) Concomitant adenocarcinoma & \\
$\quad$ Stage III & 2 \\
Neoplasms with endocrine significance & 17 \\
Granulosa cell carcinoma & \\
$\quad$ Stage III & \\
Total & \\
\hline
\end{tabular}

We used a new method to evaluate the effect of antineoplastic drugs on tumour volume. ${ }^{12}$ Radio- paque indicators (tantalum balls $0.8 \mathrm{~mm}$ diameter) were placed at operation on the surface of the tumour. Their positions were then determined by an $x$-ray stereophotogrammetric method and the tumour volume calculated by computer. In this way we measured the effect of the combined therapy in eight patients by the change in size of their tumour. The disease was said to be stationary when any change was no more than $\pm 10 \%$; to have regressed when it had diminished by more than $10 \%$; and to have progressed when it had increased by more than $10 \%$. Regression was noted in five of the eight patients for a period of 4-12 months. In one patient the lesion was stationary and in another it progressed.

Twelve of the 17 patients had ascites requiring repeated laparocentesis. The primary tumours in these patients were serous adenocarcinoma except in one who had a granulosa cell carcinoma. Treatment with tranexamic acid was followed by complete regression of ascites in six patients and at least a doubling of the intervals between laparocenteses in five of the remaining six.

The survival time of the patients with stage III carcinomas cannot yet be given because some of them were still alive after two years follow-up. The mean survival time in the five patients with serous adenocarcinoma stage IV was eight months.

The static effect of tranexamic acid might be due to encapsulation of the tumours by fibrinoid substance. ${ }^{10}$ This was particularly noticeable in somecases that had been treated for a long time, but in several cases very little or no stroma tissue was found. This suggests that tranexamic acid has a direct effect on the formation of neoplastic vessels. In fact, we found hardly any stroma round transplants of ovarian tumours grafted in the athymic nude mice and treated with tranexamic acid, in contrast to what is seen round tumours grafted in non-treated animals. Furthermore, in a patient with a parametrial haemangioma visualised by angiography the neoplastic vessels regressed completely after two years' treatment with tranexamic acid.

\section{Conclusion}

Tranexamic acid is thus a new agent capable of interfering with tumour growth. It has no cytotoxic effects. Besides its effect on ascites, which in most cases regresses, it prevents the proliferation of vessels and thereby has a static effect on tumour growth. The effect of cytostatics on advanced malignant tumours is often decisive. By starting treatment of advanced tumours with combined tranexamic acid and cytostatics the often good initial effect of the cytostatics should enable tranexamic acid to exert its prolonged effect. 
This work was supported by grant B80-17X-0452306C from the Swedish Medical Research Council.

\section{References}

${ }^{1}$ Carrel A. A method for the physiological study of tissues in vitro. J Exp Med 1923;38:407-18.

${ }^{2}$ Fischer A. Mechanism of the proteolytic activity of malignant tissue cells. Nature 1946;157:442.

${ }^{3}$ Fischer A. The application of soybean inhibitor in tissue cultivation. Science 1949;109:611-2.

${ }^{4}$ Ingemanson-Nordqvist B, Källén B. On the use of fibrinolysin inhibitors in plasma clot tissue culture. Exp Cell Res 1960;21:232-5.

${ }^{5}$ Christman JK, Acs G. Purification and characterization of a cellular fibrinolytic factor associated with oncogenic transformation: the plasminogen activator from SV-40-transformed hamster cells. Biochim Biophys Acta 1974;340:339-47.

${ }^{6}$ Rifkin DB, Loeb JN, Moore G, Reich E. Properties of plasminogen activators formed by neoplastic human cell cultures. $J$ Exp Med 1974;139:1317-28.

7 Svanberg L, Åstedt B. Release of fibrinolytic activators from human ovarian tumours in organ culture. Ann Chir Gynaecol 1976;65:405-7.

8 Åstedt B, Holmberg L. Immunological identity of urokinase and ovarian carcinoma plasminogen activator released in tissue culture. Nature 1976; $261: 595-7$.

${ }^{9}$ Holmberg L, Bladh B, Åstedt B. Purification of urokinase by affinity chromatography. Biochim Biophys Acta 1976;445:215-22.

10 Åstedt B, Glifberg I, Mattsson W, Tropé C. Arrest of growth of ovarian tumor by tranexamic acid. JAMA 1977;238:154-5.

${ }^{11}$ Åstedt B, Mattsson W, Tropé C. Treatment of advanced breast cancer with chemotherapeutics and inhibition of coagulation and fibrinolysis. Acta Med Scand 1977;201:491-3.

${ }^{12}$ Tropé C, Selvik G, Kullander S, Mattsson W, Mühlow A, Åstedt B. Antineoplastic-drug effect evaluated with a new $x$-ray stereophotographic measurement of the tumour volume. Ann Chir Gynaecol 1978;67:82-4. 